\title{
Supercélula en un entorno de baja cizalladura
}

https://doi.org/10.31978/639-19-010-0.585

\author{
Manuel Lara Jaén¹ (mlaraj@aemet.es)
}

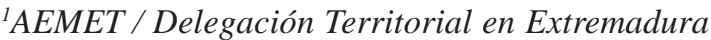

\begin{abstract}
RESUMEN
La existencia de elevada cizalladura vertical en los primeros kilómetros de la atmósfera se considera un elemento necesario en el modelo conceptual habitual de convección supercélular. El 17 de mayo de 2017 se registró en la provincia de Badajoz una tormenta con claros rasgos supercelulares en un entorno de baja cizalladura. En primer lugar se describe el entorno sinóptico, mostrando la escasa cizalladura prevista por HIRLAM y se ofrece como validación una estimación del perfil del viento obtenido con los vientos del producto HRW del SAF de nowcasting en la proximidad. Utilizando imágenes radar, se muestra la evolución de las principales características de la tormenta que permiten clasificarla como supercelular, algunas de sus peculiaridades y su cinemática. También se muestra el diferente comportamiento eléctrico de los dos miembros. Finalmente se exponen algunas posibles explicaciones a este desarrollo poco ajustado al modelo habitual de supercélula.
\end{abstract}

PALABRAS CLAVE: supercélula; cizalladura; storm-splitting; high resolution winds; radar.

\section{INTRODUCCIÓN}

La definición de supercélula es sencilla: una tormenta con un profundo y persistente mesociclón en su corriente ascendente; véase por ejemplo MARKOWSKY y RicHARDSON (2010). Este mismo texto, referencia en la meteorología de mesoescala, presenta ya en su portada un fotomontaje que ilustra la idea básica de cómo se genera la rotación de eje vertical por conversión de la vorticidad horizontal asociada a la cizalladura del viento en vorticidad vertical mediante la convección. Esto ha llevado a convertir a la cizalladura en un elemento clave, pudiendo verse en distintos textos diferentes umbrales por debajo de los cuales el desarrollo supercelular se considera muy improbable, independientemente del grado de inestabilidad. Estos umbrales van desde los $20 \mathrm{~m} \mathrm{~s}^{-1}$ en algunos textos de la NOAA hasta $9 \mathrm{~m} \mathrm{~s}^{-1}$ en algunas publicaciones internas de AEMET, siempre hablando de cizalladura ambiente entre 0 y $6 \mathrm{~km}$.

Sin embargo el propio Markowsky, y otros autores, señalan que puede haber vorticidad horizontal, de origen baroclino o de otro tipo, que se puede añadir a la anterior y hacer posible el desarrollo supercelular a pesar de partir con poca cizalladura de viento.

\section{ENTORNO SINÓPTICO DEL DÍA 17 DE MAYO DE 2017}

Las figuras 1.a, 1.b y 1.c muestran la situación sinóptica del día 17 de mayo de 2017 a las 18 Z, con ausencia de gradiente de presión en superficie y vaguada en 500 hPa aproximándose a la península ibérica; en $300 \mathrm{hPa}$ en el suroeste de la misma parecen confluir los chorros polar y subtropical.

La fig. 2 muestra el sondeo previsto por HIRLAM a las $18 \mathrm{Z}(\mathrm{H}+6)$ sobre las coordenadas $\left(39,0^{\circ} \mathrm{N},-6,0^{\circ} \mathrm{W}\right)$, cerca de la localidad de Don Benito sobre la que pasó el miembro izquierdo sobre las 18:10Z, y la tabla 1 muestra un resumen de los principales parámetros del mismo. Los valores de los índices de estabilidad 

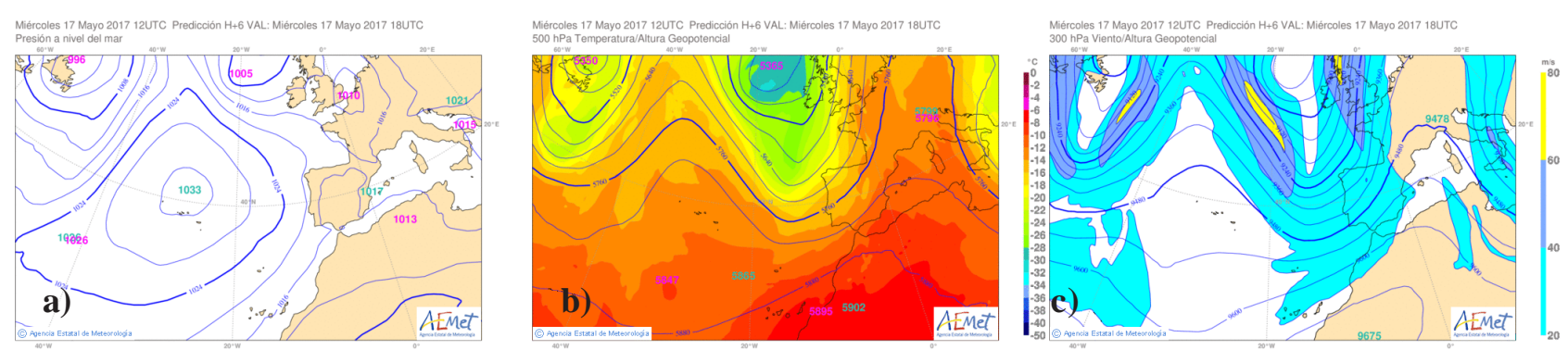

Figura 1. a) Mapa de presión en superficie, b) temperatura y altura de geopotencial en 500 hPa y c) altura de geopotencial y velocidad del viento en $300 \mathrm{hPa}$ para las $18 \mathrm{Z}$ del 17 de mayo de 2017.

clásicos lifted index (LI) y total de totales (TT) marcan clara inestabilidad. La EMA de Don Benito registró ese día una temperatura máxima de $32,0^{\circ} \mathrm{C}$ a las 15:00 Z, y a la hora del sondeo previsto, 18:00 Z, la temperatura registrada por la EMA $\left(29,0^{\circ} \mathrm{C}\right)$ superaba la temperatura de disparo (TDIS), estimada en $27,1^{\circ} \mathrm{C}$. Por último, el alto valor de la energía potencial convectiva disponible (CAPE) y el bajo valor de la energía de inhibición convectiva $(\mathrm{CIN})$ refuerzan la idea de una atmósfera inestable.

Pero lo más interesante de este sondeo no es la inestabilidad, que tampoco se puede considerar ni mucho menos extrema, sino el débil viento en niveles bajos y medio-bajos, por ejemplo $15 \mathrm{kt}\left(7,7 \mathrm{~m} \mathrm{~s}^{-1}\right)$ en el nivel de $700 \mathrm{hPa}$. Con este perfil, la helicidad relativa a la tormenta (SRH) calculada hasta $3 \mathrm{~km}$, resulta nula, y otros parámetros utilizados en el diagnóstico de convección supercelular como el número de Richardson global (NRG) y el índice helicidad-energía (EHI) muestran también valores incompatibles, en principio, con la formación de supercélulas.

Es cierto que se observa un aumento de la velocidad del viento en las cercanías de 500 hPa y que eso lleva a la cizalladura hasta $6 \mathrm{~km}$ (CIZBL6) a un valor de $5,0 \mathrm{~m} \mathrm{~s}^{-1}$, poco significativo al efecto que nos ocupa, pero no despreciable.

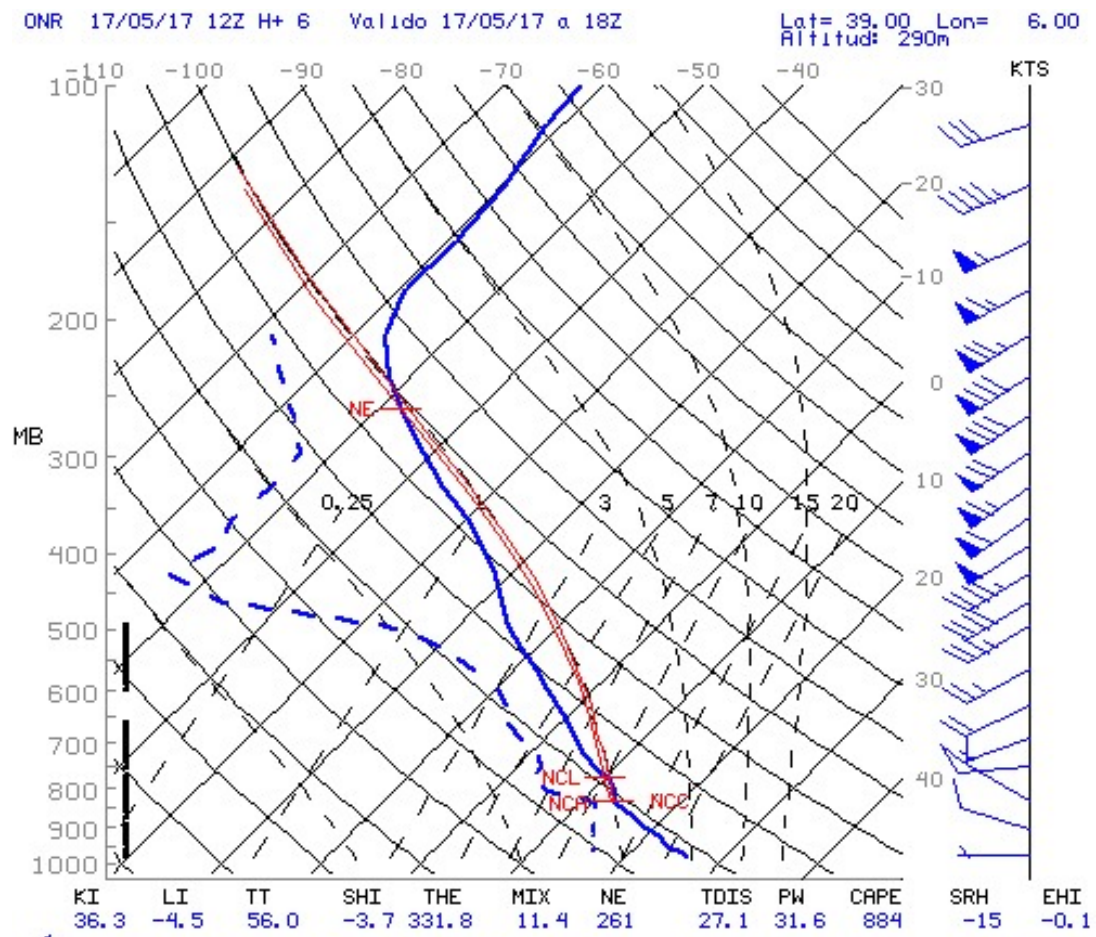

Figura 2. Sondeo previsto por HIRLAM a las $18 \mathrm{Z}(\mathrm{H}+6)$ en $\left(39,0^{\circ} \mathrm{N},-6,0^{\circ} \mathrm{W}\right)$, cerca de la localidad de Don Benito sobre la que pasó el miembro izquierdo sobre las 18:10 Z.

\begin{tabular}{|l|r|}
\hline $\mathrm{LI}$ & $-4,5$ \\
\hline $\mathrm{TT}$ & 56,0 \\
\hline TDIS & $27,1 \mathrm{pC}$ \\
\hline CAPE & $884 \mathrm{~J} \mathrm{~kg}^{-1}$ \\
\hline CIN & $9 \mathrm{~J} \mathrm{~kg}^{-1}$ \\
\hline SRH & $-15 \mathrm{~m}^{2} \mathrm{~s}^{-2}$ \\
\hline CIZBL6 & $5,0 \mathrm{~m} \mathrm{~s}^{-1}$ \\
\hline NRG & 70 \\
\hline EHI & $-0,1$ \\
\hline
\end{tabular}

Tabla 1. Resumen de parámetros termodinámicos del sondeo HIRLAM previsto de la figura 2. 
Se han utilizado imágenes del producto de satélite High Resolution Winds (HRW) del SAFNWC/MSG para intentar verificar la validez del sondeo de la figura 2 previsto por HIRLAM. Mediante un análisis subjetivo manual y utilizando imágenes entre 16:00 Z y 17:30 Z se ha estimado un perfil del viento en la proximidad de la supercélula con el resultado que se muestra en la tabla 2. La figura 3 muestra una de las imágenes utilizadas, la correspondiente a las 16:30 Z, en la que se ha indicado con una flecha verde uno de los trazadores que muestra un valor de $10 \mathrm{kt}\left(7,1 \mathrm{~m} \mathrm{~s}^{-1}\right)$ en la capa 500-600 hPa. El perfil estimado de viento viene a confirmar el escaso viento de $290-300^{\circ}$ hasta $500 \mathrm{hPa}$ y el brusco aumento hasta $65 \mathrm{kt}$ con giro contra-reloj hasta situarse en $220-230^{\circ}$.

Así pues, puede decirse hasta cierto punto que el título de este trabajo es engañoso, ya que sí que tenemos cizalladura, si bien hay que irse hasta niveles altos (deep layer) para encontrarla.

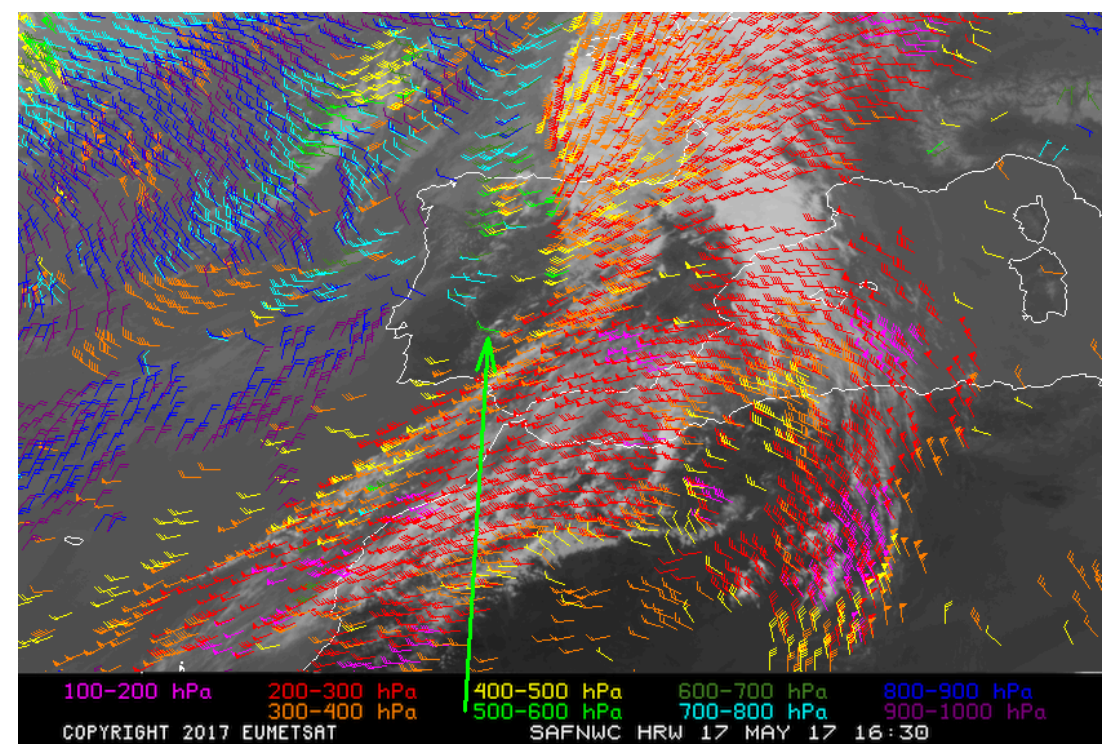

Figura 3. Imagen del producto High Resolution Wind (HRW) del SAF de nowcasting a las 16:30 Z; una de las utilizadas para generar una estimación del perfil de la velocidad del viento

en la proximidad del sondeo de la figura 2. La flecha verde indica el escaso viento en la capa 500-600 hPa.

\begin{tabular}{|c|c|c|}
\hline Nivel (hPa) & Vel (kt) & Dir $\left(^{\circ}\right)$ \\
\hline 250 & 65 & 230 \\
\hline 350 & 65 & 230 \\
\hline 450 & 45 & 220 \\
\hline 550 & 10 & 290 \\
\hline 650 & 8 & 290 \\
\hline 750 & 5 & 290 \\
\hline 850 & 5 & 300 \\
\hline Sfc (emas) & 5 & 330 \\
\hline
\end{tabular}

Tabla 2. Perfil de velocidad del viento estimado manualmente del análisis de imágenes HRW entre 16:00 Z y 17:30 Z en la proximidad del sondeo de la figura 2.

\section{EVOLUCIÓN DE LA TORMENTA Y RASGOS SUPERCELULARES MAS NOTABLES}

Podemos tomar como hora de inicio las 16:20 Z; en esos momentos es solo una pequeña célula aislada pero cuyo ECOTOP alcanza ya los $6 \mathrm{~km}$, alcanzando los $8 \mathrm{~km}$ diez minutos más tarde. La tormenta toma de inicio una forma alargada, alineándose con los vientos en altura. A las 17:10 Z comienza la división (splitting), que seguramente no es ajena a la interacción con una célula de corta vida que se desarrolló algo más al sur. Podemos considerar que a las 17:30 Z la división es completa, véase figura 4.

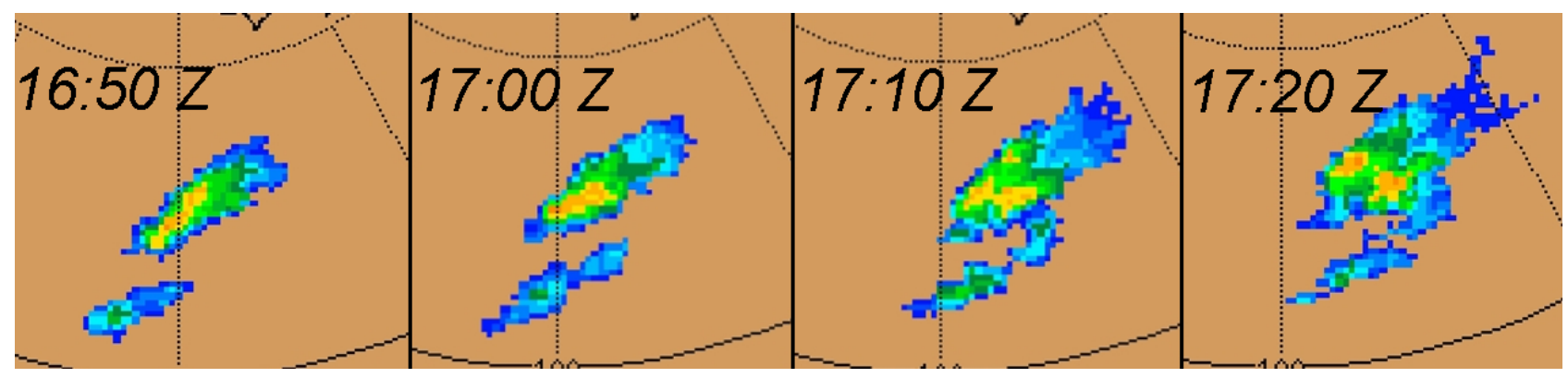

Figura 4. Secuencia de 4 PPI de reflectividad entre 16:50 Z y las 17:20 Z mostrando la división, «V-Notch» y la aparente interacción con la célula situada más al sur. 
El miembro derecho (RM) se puede considerar que acaba a las 19:40 Z, aunque en la última media hora ya haya perdido buena parte de su estructura y organización. En cambio el miembro izquierdo (LM) tuvo una mayor duración, hasta las 20:20 Z, siendo esta una de las peculiaridades que nos encontramos en esta supercélula. Tenemos, por tanto, dos rasgos característicos de supercélula, la longevidad, 4 horas, y un splitting o división.

A partir de aquí los miembros evolucionan de manera muy diferente. Aunque a las 17:20Z los PPI de ambos miembros son relativamente parecidos, superando ambos los $55 \mathrm{dBZ}$, su estructura vertical es muy distinta, mostrando el LM unos echotops mucho más bajos. Media hora más tarde esa diferencia entre ambos miembros es más notable aún: aunque ambos superan los 57 dBZ en el PPI, el RM es más extenso, y mientras los echotops del LM no alcanzan los $10 \mathrm{~km}$ el RM alcanza los $13 \mathrm{~km}$ y mantiene un área amplia por encima de $10 \mathrm{~km}$. La figura 7 muestra esta diferencia en la estructura vertical de los miembros a las 17:40 Z.

El hecho de que el RM se desarrolle más y sea más longevo que el LM es lo más habitual en las supercélulas, y este comportamiento dentro del estandar continuó un tiempo, de forma que a las 18:10 Z los echotops del LM continúan sin alcanzar los $10 \mathrm{~km}$ y el RM mantiene un área de unos $50 \mathrm{~km}^{2}$ por encima de ese nivel. Pero ya en esos momentos hay detalles que se desvían algo de la evolución normal. La reflectividad en el PPI del LM ha continuado subiendo y alcanza los $60 \mathrm{dBZ}$ y presenta un gradiente elevado en el lado norte.

A partir de ese momento el RM comienza a mostrar signos claros de decaimiento aunque mantiene una amplia extensión. Mientras, el LM continúa aumentando su reflectividad en niveles bajos alcanzando 63,5 dBZ a las 19:00 Z, casi tres horas después de iniciada la tormenta, y en algunos momentos da incluso muestras de intentar una nueva división; el RM por su parte no llega ya a los $50 \mathrm{dBZ}$. También en esos momentos, la desviación respecto de la trayectoria inicial del LM se intensifica (tabla 3).

Aparte de la longevidad dicha, propiedad que al parecer fue el origen del término supercélula para este tipo de tormentas, vamos a ver otros rasgos supercelulares que podemos encontrar en este episodio. La existencia de un mesociclón, o mesoanticiclón, más que un rasgo, es la característica que define a una supercélula. Si bien no siempre ocurre que el mesociclón esté dentro de la cobertura Doppler del radar, y otras veces, aun estando dentro, no se encuentra en una zona de observación óptima.

En nuestro caso se ha podido localizar la firma del mesociclón en el RM en las imágenes de viento Doppler de 18:16Z y 18:26 Z. En la figura 5.a puede verse la imagen de viento Doppler de las 18:16Z que muestra el dipolo definido por colores rojos (velocidades positivas) y verdes (velocidades negativas) separados por una radial, indicando rotación anticiclónica. En la figura 5.b puede verse la reflectividad para esa misma hora que muestra claramente un gancho en las cercanías.

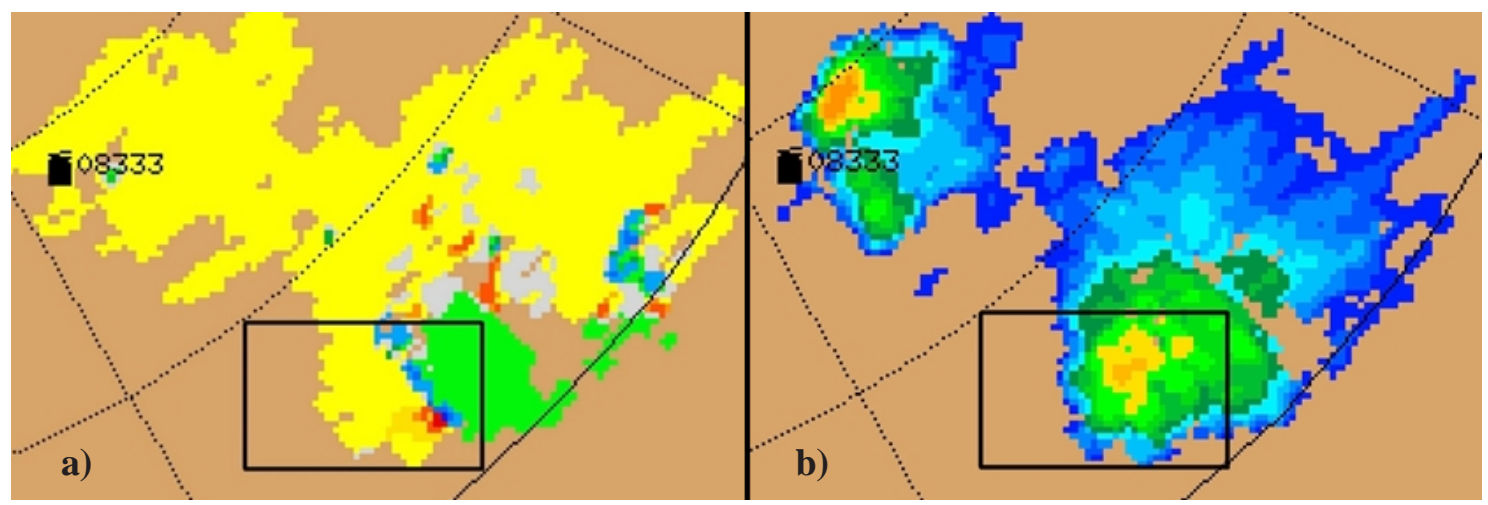

Figura 5. a) PPI velocidad de viento Doppler a las 18:16 Z, b) PPI de reflectividad a las 18:16 Z. 
Para el caso del LM se ha encontrado un patrón compatible con mesoanticiclón en la imagen del viento Doppler de las 18:06Z, figura 6.a, apreciándose también en la imagen de reflectividad un gancho en el flanco trasero, figura 6.b. Pueden observarse en estas imágenes zonas con señal menor o nula, lo cual es debido a que los dos miembros en su desplazamiento se encuentran con sectores en los que el haz del radar está parcialmente bloqueado por la sierra de Montánchez, lo que seguramente dificulta detectar el mesoanticiclón en las imágenes siguientes.
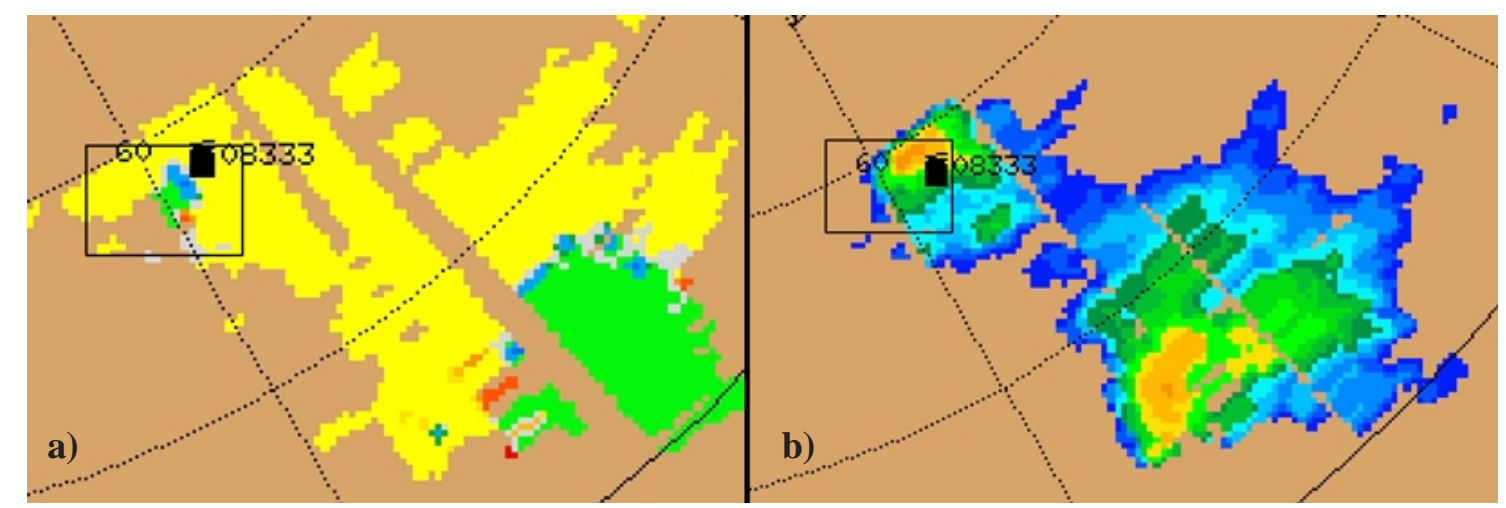

Figura 6. a) PPI velocidad de viento Doppler a las 18:06 Z, b) PPI de reflectividad a las 18:06 Z.

Un aspecto distintivo de las tormentas supercelulares es la presencia en los cortes verticales de estructuras abalconadas o ganchos, y las llamadas zonas acotadas de eco débil (BWER). La figura 7.b muestra sobre la imagen de reflectividad (CAPPI $1 \mathrm{~km}$ ) las rectas que definen dos cortes verticales realizados a los miembros, LM y RM, con los resultados de los cortes mostrados respectivamente en las figuras 7.a y 7.c; todas las imágenes en la figura 7 son de las 17:40 Z, justo tras el splitting. Puede observarse en el miembro derecho la estructura abalconada y la BWER. Por el contrario el LM mantiene un desarrollo mucho menor, sin ecos elevados ni ganchos verticales.

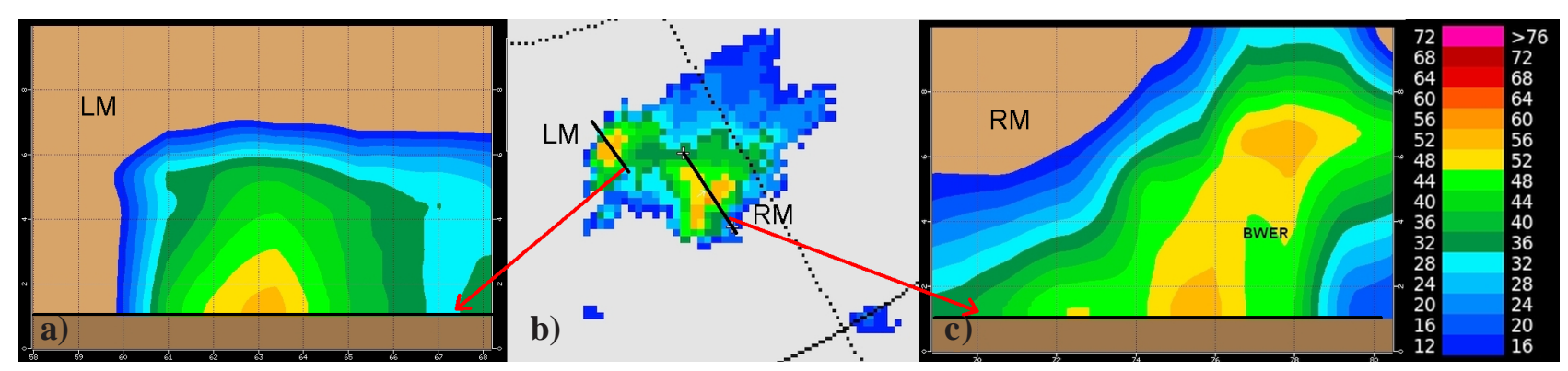

Figura 7. a) Corte vertical en la reflectividad del miembro LM, b) imagen de reflectividad CAPPI 1 a las 17:40 Z, con la posición de las rectas de cortes verticales en LM y RME, c) corte vertical en la reflectividad del miembro RM. El miembro LM apenas alcanza los $7 \mathrm{~km}$ mientras que el RM supera ampliamente los $10 \mathrm{~km}$ y muestra una zona acotada de eco débil (BWER).

\section{PASO DEL LM POR DON BENITO Y ACTIVIDAD ELÉCTRICA DE LA TORMENTA}

La tormenta a pesar de su duración y amplio recorrido, apenas tuvo impacto conocido, ya que atravesó áreas poco pobladas de la provincia de Badajoz. Tampoco se conocen noticias sobre posible tornado asociado. Solo el paso del LM por la localidad de Don Benito a las 18:10 Z dejó granizo, registros notables en la EMA y algunas imágenes impactantes, como la fotografía de la figura 8.a. En la figura 8.b podemos ver que el único rastro del rápido paso de la tormenta en la gráfica de velocidad del viento fue la racha máxima diezminutal de 

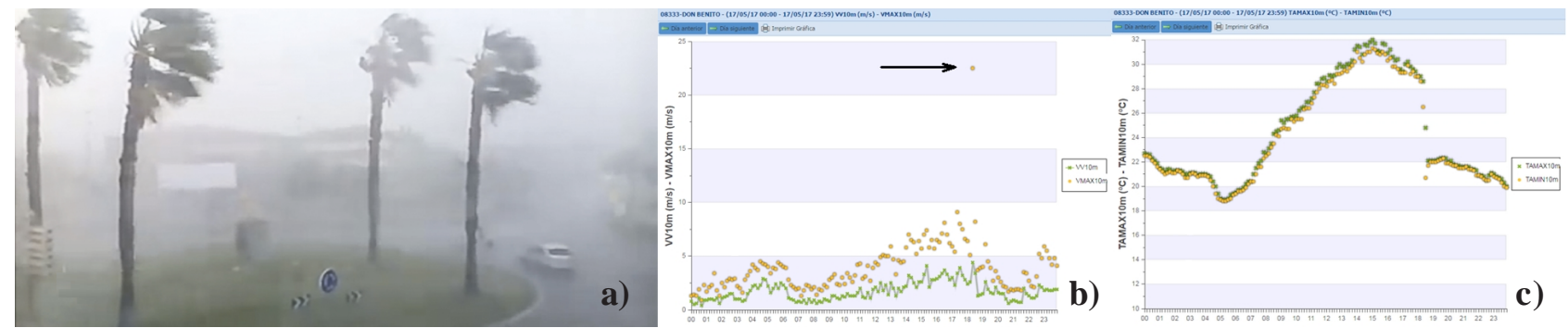

Figura 8. a) Fotografía con los efectos al paso del miembro izquierdo por Don Benito a las 18:10 Z.

b) Registro de velocidad y c) registro de temperatura de la EMA de Don Benito.

las 18:10 Z, $82 \mathrm{~km} / \mathrm{h}$, marcada con una flecha en la gráfica. Sin embargo en la gráfica de temperatura (figura 8.c) el paso es mucho más espectacular, con un acusado descenso del que no se recupera al quedar dentro de la bolsa fría.

En el momento del paso del LM por Don Benito, el RM empieza a mostrar signos de agotamiento, y a pesar de mantener una extensión superior, sus reflectividades son menores que las del LM que, en esos momentos, sobre Don Benito alcanzan los 63 dBZ en el PPI.

La actividad eléctrica de la tormenta no se puede decir que fuera espectacular en cuanto a número de descargas, pero sí tiene aspectos destacables. En primer lugar hay que decir que la actividad eléctrica tiene paralelismo con el desarrollo de los miembros. Al igual que el RM se desarrolló rápidamente para decaer relativamente pronto y el LM tuvo un desarrollo más lento pero más durarero, el RM comenzó bastante antes a producir descargas que el LM y también terminó antes.

El segundo aspecto a reseñar es que la mayoría de las descargas del RM son positivas y tienden a estar agrupadas mientras que las del LM son negativas y que, una vez que el LM empezó a generarlas, precisamente al aproximarse a Don Benito, lo hizo de manera más o menos uniforme (figura 9).

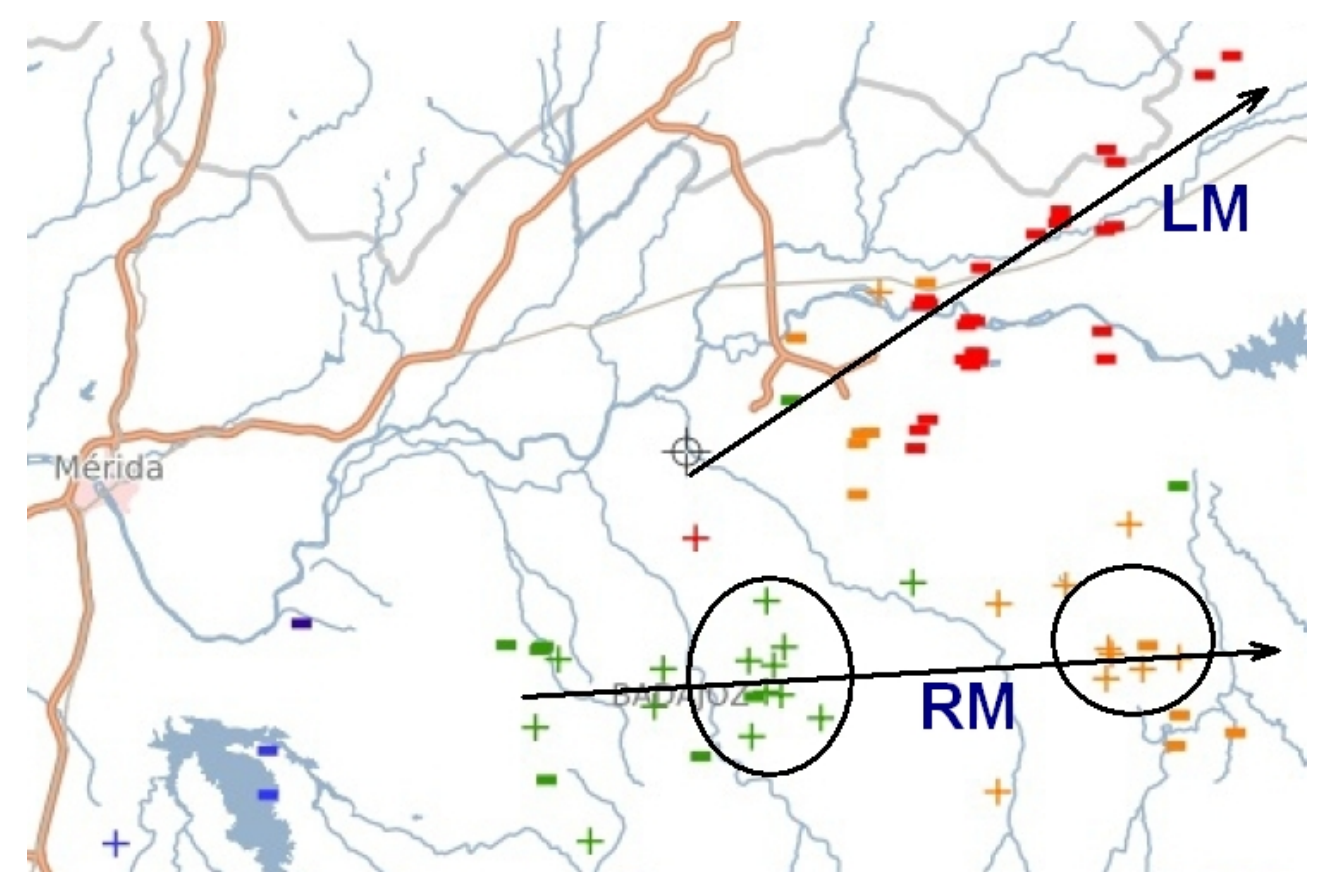

Figura 9. Descargas eléctricas asociadas a la tormenta; los colores indican el tiempo. Las descargas en rojo indican que se produjeron entre 18:30 Z y 19:00 Z y puede verse que se corresponden todas con el LM, siendo todas, menos una, negativas. En cambio las descargas del RM son en su mayoría positivas, y todas registradas antes de las 18:30 Z (colores verde y naranja). 


\section{ESTUDIO CINEMÁTICO. APLICACIÓN MANUAL DEL MÉTODO DE BUNKERS}

Utilizando imágenes de VIL se han determinado las velocidades de la tormenta cada treinta minutos con el resultado expresado en la tabla 3. Antes de la división encontramos que el desplazamiento de la tormenta era en la dirección $073^{\circ}$ a $26 \mathrm{~km} \mathrm{~h}^{-1}$. Tras la división ambos miembros se aceleran, aunque el LM aumenta su velocidad de manera gradual y el RM lo hace de manera brusca. La velocidad media del LM durante la hora siguiente a la división fue de $37 \mathrm{~km} \mathrm{~h}^{-1}$, mientras que la del $\mathrm{RM}$ fue de $46 \mathrm{~km} \mathrm{~h}^{-1}$. Es decir el RM aumentó su velocidad en un $76 \%$ mientras que la velocidad del LM aumentó en un $42 \%$.

\begin{tabular}{|c|c|c|c|c|c|c|}
\hline \multicolumn{7}{|c|}{ Velocidad de la tormenta $\left(\mathrm{km} \mathrm{h}^{-1} /{ }^{\circ}\right.$ ) } \\
\hline Antes división & \multicolumn{7}{|c|}{ Después división } \\
\hline $17: 00$ & & $17: 30$ & $18: 00$ & $18: 30$ & $19: 00$ & $19: 30$ \\
\hline \multirow{2}{*}{$26 / 073$} & RM & $48 / 082$ & $47 / 086$ & $43 / 092$ & - & - \\
\cline { 2 - 7 } & LM & $33 / 061$ & $38 / 052$ & $39 / 061$ & $48 / 045$ & $38 / 047$ \\
\hline
\end{tabular}

Tabla 3. Velocidad de la tormenta justo antes y después de la división.

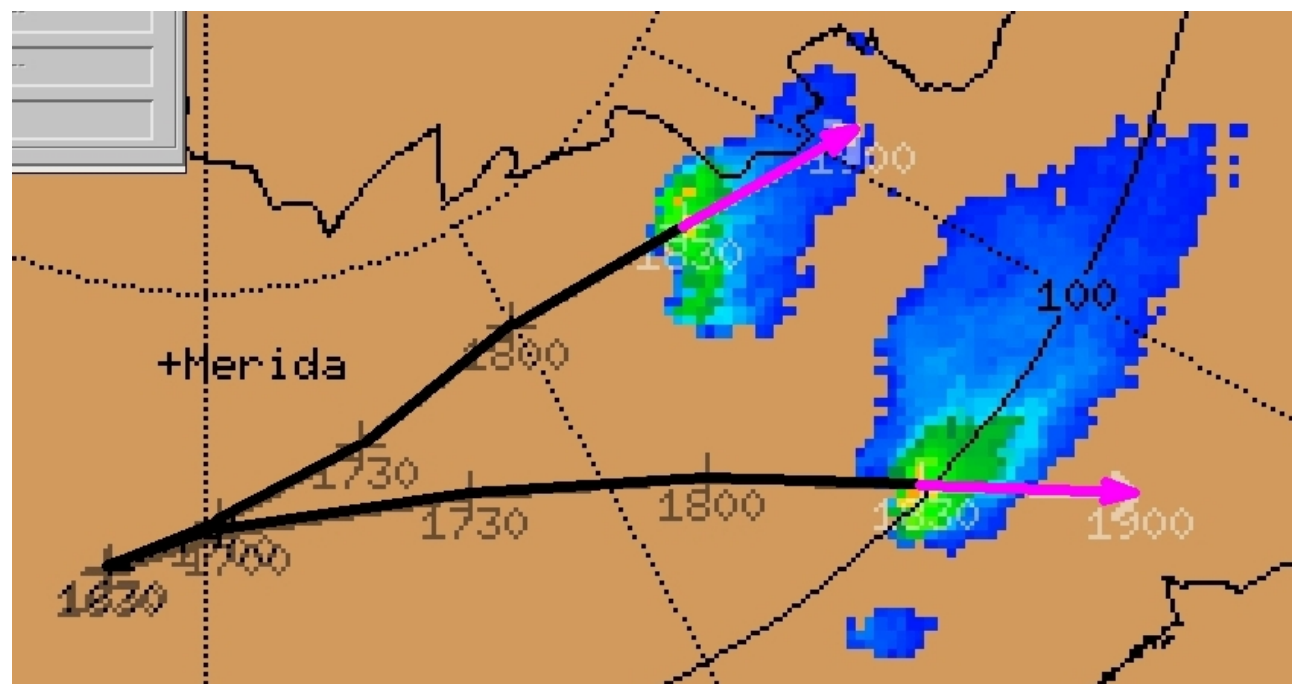

Figura 10. Trayectorias de los miembros de la tormenta hasta las 18:30 Z. Las flechas moradas son el pronóstico del sistema de IRIS para la siguiente media hora. El LM giró más al norte en su fase final.

En cuanto a las direcciones, la desviación promedio respecto al rumbo inicial para la hora siguiente a la división es casi igual para las dos miembros, $15^{\circ}$ para el LM y $14^{\circ}$ para el RM, dando por tanto una dirección de $058^{\circ}$ para el LM y $087^{\circ}$ para el RM. Hay que indicar que el LM, más longevo como se ha dicho que el $\mathrm{RM}$, acentuó su desviación en la hora siguiente hasta alcanzar los $25^{\circ}$.

El movimiento de la supercélula es una variable fundamental ya que sirve de base para el cálculo de otras variables importantes en la convección severa, como por ejemplo la helicidad relativa a la tormenta o el significant tornado parameter. Uno de los métodos más extendidos de predicción del movimiento supercelular es el propuesto por Bunkers, del que recientemente este autor ha realizado una evaluación exhaustiva de sus errores junto con los errores del método de Rasmussen-Blanchard (BUNKERS, 2018). Ambos métodos están basados en la cizalladura ambiental y son invariantes de Galileo, y Bunkers encuentra que ambos funcionan bien en general, pero que en ocasiones los errores pueden ser grandes e indica en qué situaciones estos métodos ofrecen menos fiabilidad. La expresión matemática del método de Bunkers para la estimación de la velocidad del miembro derecho según Bunkers puede verse en la ecuación 1: 


$$
\overrightarrow{\boldsymbol{V}}_{R M-B U N}=\overrightarrow{\boldsymbol{V}}_{M 06}+\mathrm{D}\left(\frac{\frac{\partial \overrightarrow{\boldsymbol{V}}}{\partial z} \times \overrightarrow{\boldsymbol{k}}}{\left|\frac{\partial \vec{V}}{\partial z}\right|}\right)
$$

donde $\vec{V}_{R M-B U N}$ es la velocidad del RM estimada por este método, $\vec{V}_{M 06}$ es el viento medio entre 0 y $6 \mathrm{~km}$ promediado en altura, el término entre paréntesis representa un vector unitario normal y a la derecha del vector cizalladura entre 0-0,5 km y 5,5-6,0 km y D es una desviación respecto del viento medio, fijada en $7,5 \mathrm{~m} \mathrm{~s}^{-1}$.

Los datos necesarios para la aplicación del método, $\vec{V}_{M 06}, \vec{V}_{0-0,5}$ y $\vec{V}_{5,5-6}$, se han obtenido del perfil de la tabla 2 con las interpolaciones necesarias y su inevitable incertidumbre adicional, obteniéndose los siguientes valores en formato $(\mathrm{u}, \mathrm{v}) \mathrm{y}$ con unidades $\mathrm{m} \mathrm{s}^{-1}$ :

$\vec{V}_{M 06}=(4,5,0,9)$,

$\vec{V}_{0-0,5}=(1,8,-2,1)$,

$\overrightarrow{\boldsymbol{V}}_{5,5-6}=(12,3,2,2)$.

Con ellos el resultado es $\vec{V}_{R M-B U N}=(7,3,-7,8)$ mientras que la observación radar nos da $\vec{V}_{R M-R A D}=(13,1,1,8)$. La figura 11 ilustra estos resultados.

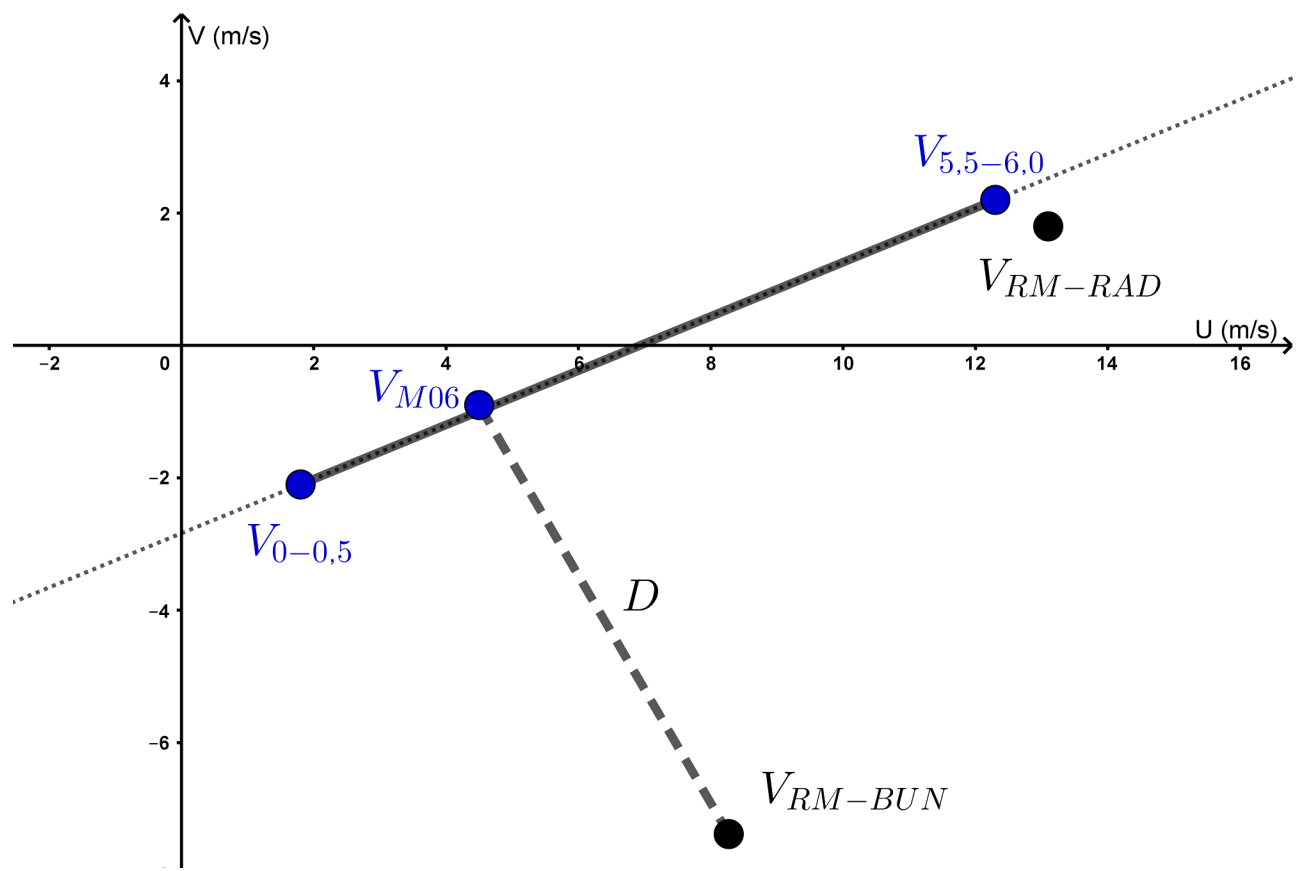

Figura 11. Situación del RM en el espacio (u, v) según la observación radar, $\vec{V}_{R M-R A D}$, y según el método de Bunkers, $\vec{V}_{R M-B U N}$.

La discrepancia entre ambas estimaciones es notable. El método de Bunkers subestima el módulo de la velocidad con 10,7 frente a 13,2 $\mathrm{m} \mathrm{s}^{-1}$, aunque el error es más importante en la dirección que en el módulo, de manera que la observación radar sitúa al RM en el primer cuadrante y el método de Bunkers lo coloca bastante alejado en el segundo. En el trabajo citado Bunkers señala algunas situaciones en las que tanto su método como el de Rasmussen-Blanchard deben ser manejados con menos confianza, citando en concreto las hodógrafas que presentan un giro marcado en niveles medios y altos como es este. 


\section{POSIBLES EXPLICACIONES DEL DESARROLLO SUPERCELULAR}

J. M. L. DAHL (2006) muestra en su trabajo el caso similar de una supercélula en Alemania, también durante un mes de mayo, desarrollada en un entorno con cizalladura despreciable en los primeros kilómetros de la atmósfera y sugiere algunas posibles explicaciones. Considera que posibles alteraciones locales o mesoescalares del flujo en niveles bajos pueden compensar el déficit de vorticidad horizontal causado por la ausencia de cizalladura vertical. Entre estas posibles alteraciones cabe pensar en factores orográficos; Dahl cita canalizaciones del flujo en atmósferas con estratificación neutra, líneas de convergencia y fronteras generadas por flujos de salida.

En este caso podemos ver en la figura 4, como una tormenta situada más al sur parece interaccionar con nuestra tormenta justo antes de la división que ocurrió sobre las 17:10 Z. La imagen de viento Doppler de la figura 12 es de las 16:56 Z, y muestra flujo con componente hacia la supercélula procedente de la tormenta situada al sur (color verde). Por otro lado la figura 13 muestra las posiciones de las dos tormentas en Google Earth, y es muy llamativo comprobar

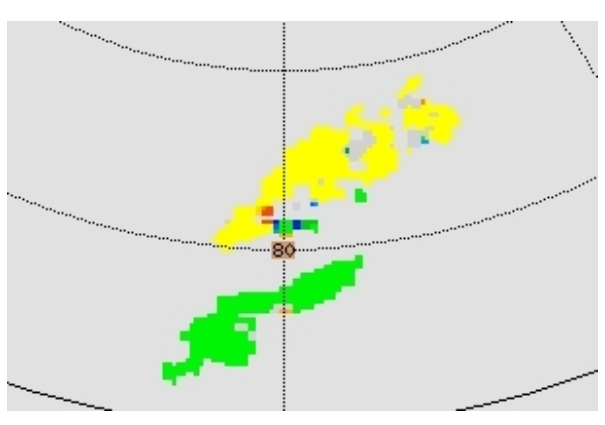

Figura 12. Imagen de viento Doppler de las 16:56 Z. Color verde indica componente hacia el radar. como la división de nuestra tormenta se produce sobre las montañas que bordean el lado norte de la presa de Alange, y que el flujo de salida de la tormenta situada al sur ha sobrevolado unos $5 \mathrm{~km}$ de lago a $260 \mathrm{~m}$ y luego se ha tenido que elevar por encima de los $500 \mathrm{~m}$. Este flujo pudo haber aportado vorticidad baroclina suficiente para compensar la insuficiencia de vorticidad asociada a la cizalladura.

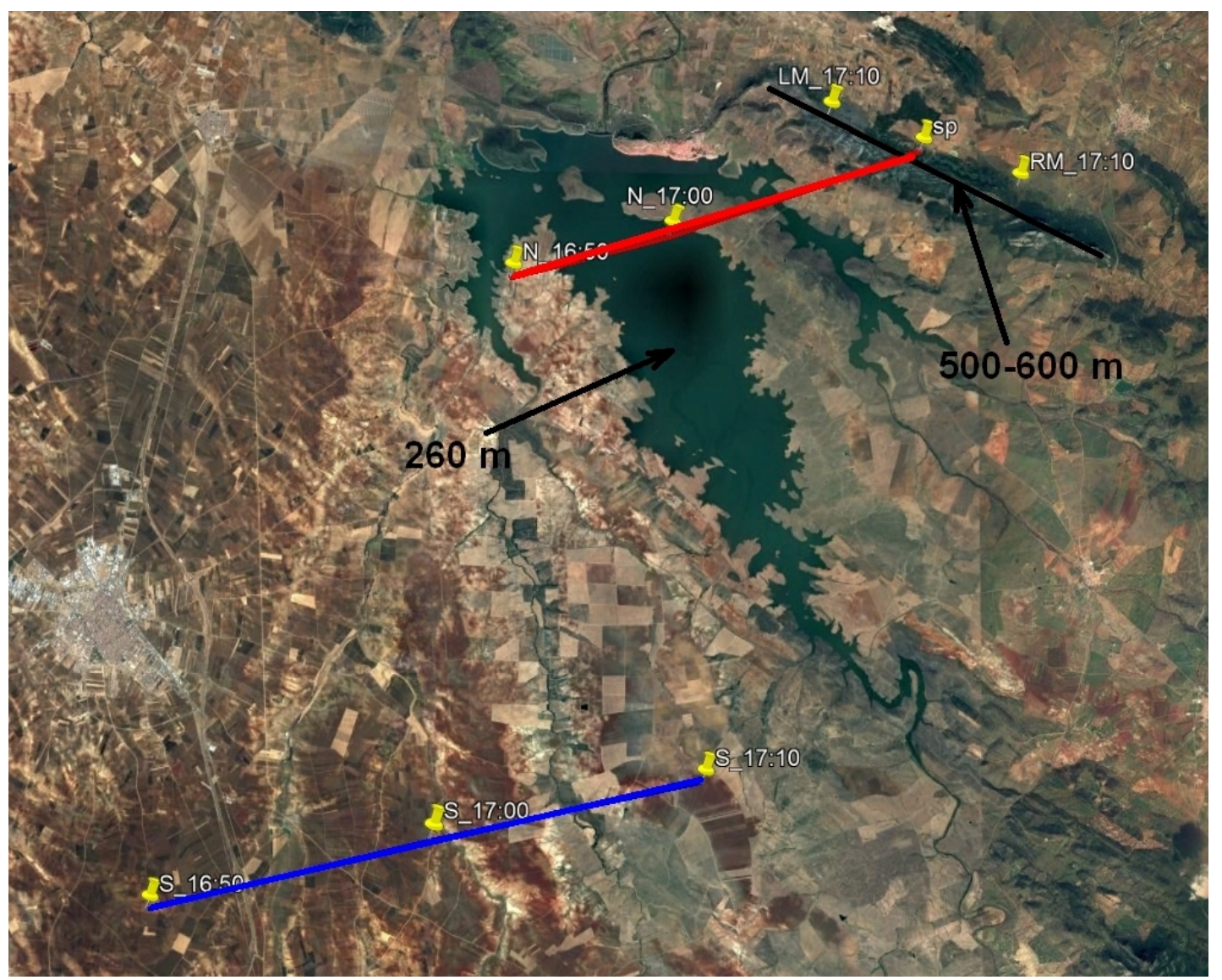

Figura 13. Imagen Google Earth mostrando en rojo las posiciones (N_*) de la supercélula antes de la división, y en azul las posiciones $\left(\mathrm{S}_{-} *\right.$ ) de la tormenta de vida breve que discurrió más al sur. La localidad al suroeste del pantano es Almendralejo. 


\section{CONCLUSIONES}

Se ha descrito en este trabajo la evolución de una tormenta supercelular que se ha desarrollado en un ambiente de poca cizalladura en niveles bajos, lo cual, en principio, es algo poco compatible con el mecanismo aceptado para la generación del mesociclón. Se ha comprobado que el método de Bunkers ha fallado en la predicción del RM, lo cual era de esperar ya que es un método basado en la hodógrafa que, en nuestro caso, está muy lejos de ser una hodógrafa supercelular típica.

Sería deseable determinar si casos como este que se desvían del paradigma son realmente excepcionales, o si no lo son tanto; en cualquier caso parece muy razonable el extender, tal y como se ha comenzado a hacer, el cálculo de la cizalladura en los parámetros de los sondeos hasta los $8 \mathrm{~km}$, y de la helicidad relativa hasta los $6 \mathrm{~km}$.

\section{REFERENCIAS}

Bunkers, M. J., 2018. Observations of Right-Moving Supercell Motion Forecast Errors. Weather and Forecasting, 33 (1), 145-159.

Dahl, J. M. L., 2006. Supercells - Their Dynamics and Prediction. Thesis, Freie Universität Berlin. http://www.estofex.org/files/dahl_thesis.pdf.

Markowski, P. y Richardson, Y., 2010. Mesoscale Meteorology in Midlatitudes, editorial Wiley-Blackwell. 